\title{
A EXPERIÊNCIA DA SUJEIÇÃO À AUTORIDADE POLICIAL \\ Notas sobre a articulação entre cognição e emoção na vida pública*
}

\section{Maria Claudia Coelho}

Universidade do Estado do Rio de Janeiro (Uerj), Rio de Janeiro - RJ, Brasil. E-mail: mccoelho@bighost.com.br

\section{João Trajano Sento-Sé}

Universidade do Estado do Rio de Janeiro (Uerj), Rio de Janeiro - RJ, Brasil. E-mail: joaotrajano@uol.com.br

\section{Raquel Brum Fernandes}

Colégio Pedro II, Rio de Janeiro - RJ, Brasil. E-mail: raquel_bfs@hotmail.com

\section{Fábio Rios}

Universidade do Estado do Rio de Janeiro (Uerj), Rio de Janeiro - RJ, Brasil. E-mail: fabiodanielsr@gmail.com

DOI: http//dx.doi.org/10.17666/3190151-165/2016

\section{Introdução}

O presente trabalho aborda a experiência da autoridade policial do ponto de vista da sujeição, com base em relatos de cidadãos de camadas médias e altas, moradores do estado do Rio de Janeiro. Seu desenho examina situações de interação entre policiais e esses cidadãos, oferecendo, assim, um contraponto ao viés predominante na literatura especializada em policiamento das ciências sociais, que costuma privilegiar a interação entre policiais e segmentos das camadas populares.

* Este artigo apresenta resultados parciais do projeto "O exercício da autoridade no sistema de justiça criminal", desenvolvido com apoio da Faperj no Programa APQ1 (2011-2013). Uma primeira versão do trabalho foi apresentada na X Reunión de Antropología del Mercosur, Córdoba, 10 a 13 de julho de 2013.

Aprovado em 29/09/2015
$\mathrm{O}$ artigo traz um recorte dos resultados obtidos pelo projeto "O exercício da autoridade no sistema de justiça criminal", que abordou o exame de duas "cenas de exercício da autoridade": as revistas de malas em aeroportos e as abordagens nas operaçōes da Lei Seca no Rio de Janeiro. O objetivo é investigar a articulação, na construção dessas experiências, entre os planos cognitivo (concepçôes de autoridade, legalidade, poder, violência etc.) e emotivo, visto que a menção a sentimentos tais como medo, vergonha e constrangimento revela a atuação de fatores emocionais no modo como os entrevistados vivenciam e reagem à autoridade policial. Dessa forma, a análise busca contribuir com duas áreas de investigação, em um movimento de mão dupla: (a) o campo de estudo das emoções na vida pública, ressaltando os papéis desempenhados pelos sentimentos na configuração de relações de autoridade e controle social; e (b) o campo dos estudos sobre policiamento, abordado do ponto de vista da experiência subjetiva dos atores sociais envolvidos. 
Em sua primeira fase, o projeto focalizou a experiência do exercício da autoridade do ponto de vista de policiais integrantes das equipes da Operação Lei Seca. Com base em entrevistas em profundidade, identificamos alguns traços característicos da concepção e da performance da autoridade que marca estilo de policiamento adotado nessa operação. Nesse trabalho, buscamos traçar um contraponto a esta experiência examinando relatos de pessoas que passaram por abordagens policiais em blitze da Lei Seca no Rio de Janeiro.

Foram realizadas doze entrevistas. A escolha dos entrevistados foi orientada exclusivamente pelo critério de ter tido a experiência de ser abordado em uma blitz da Operação Lei Seca. As entrevistas versaram sobre essa experiência, privilegiando os seguintes aspectos: (a) percepção dos entrevistados sobre os critérios policiais para a escolha dos veículos abordados; (b) construção de estratégias para a não adequação a esses que seriam os critérios adotados pela polícia; (c) interação entre os entrevistados e os policiais; (d) experiências de desrespeito, medo e/ou vergonha em relação à realização do teste do bafômetro e à abordagem policial; (e) entendimento sobre a Operação Lei Seca e seus efeitos no comportamento dos motoristas. ${ }^{1}$

O texto está dividido em quatro seçôes. Na primeira, fazemos uma breve recapitulação do modo como os estudos de polícia começam a se desenvolver no Brasil. De forma bastante sucinta, buscamos evidenciar como os padrões de atuação das polícias e seu descaso quanto ao respeito às normas legais (sobretudo em seu contato com as camadas mais pobres da população) ocuparam posição de destaque nos estudos originais do campo. Daí os estudos e as intervenções na área de segurança pública, em geral, e de ação policial, em particular, serem fortemente marcados pelo debate sobre a consagração dos direitos humanos no país. $\mathrm{Na}$ segunda seção, recuperamos em linhas gerais a concepção e a performance da autoridade policial tal como descrita pelos policiais entrevistados, arrematando com um resumo da análise à qual chegamos em texto anterior (Coelho, Sento-Sé, Silva e Zilli, 2013), que articula a autoridade policial ao riso e à polidez. A terceira seção é dedicada ao exame da experiência da sujeição à autoridade policial tal como vivenciada $\mathrm{e}$ descrita pelos entrevistados. Nas considerações fi- nais, esboçamos um comentário suscitado pela impressão geral causada na equipe pela leitura do conjunto de entrevistas realizadas com os cidadãos. Em alguma medida, seus relatos parecem "ecoar" as entrevistas dos policiais, em particular na importância dada ao tema da "educação/polidez" no trato com o cidadão; além disso, seus relatos são curiosamente desprovidos de maiores dramas e conflitos, dando uma impressão geral de "harmonia" nessa cena que envolve policiais e cidadãos. A reflexão sobre essa aparente ausência de "conflito" entre as percepçôes de policiais e cidadãos da Operação Lei Seca é o que orienta a conclusão do texto.

\section{A polícia como campo de estudos sociais}

A literatura sobre polícia, em ciências sociais, começa a ganhar corpo no Brasil em meados da década de 1980. A criação do campo coincide, portanto, com o processo de redemocratização do país. Tal coincidência tem implicações. A agenda pública exerceu influência direta nas diferentes abordagens sobre o tema das polícias desde suas origens, e tais abordagens, por sua vez, concorreram para sucessivas redefinições da agenda pública. O quadro geral em que o campo de estudos foi se configurando tem alguns traços que, vistos retrospectivamente, marcam de modo perene o seu desenvolvimento: o respeito aos direitos humanos como um imperativo a ser incorporado à nova ordem política em processo de instauração; o reconhecimento do Estado como agente violador desses preceitos; a participação das forças policiais como um dos principais focos do problema da violação sistemática dos direitos humanos por parte do Estado brasileiro. O perturbador crescimento da criminalidade urbana, verificado a partir do final dos anos de 1980, a aberta resistência das corporaçōes policiais à adequação aos novos tempos e as altas incidências de corrupção nessas corporações arremataram o cenário sombrio que concorreu para que as instituiçôes policiais se tornassem um desafio para a análise de sociólogos, historiadores, antropólogos, entre outros.

As marcas de origem são bastante evidentes nas primeiras publicações e em artigos ainda exploratórios, produzidos por pesquisadores com trajetórias 
vinculadas a outros campos de investigação. Neles, o mote principal parece apontar para a importância de se olhar seriamente para as corporaçōes policiais, entendendo-as como instâncias estratégicas do Estado e mecanismos de controle das classes populares pelo uso da força. Evidencia-se, então, a importância de se construir a massa crítica necessária para a devida compreensão do funcionamento das polícias. Pensamos, fundamentalmente, em estudos produzidos pelo então recém-fundado Núcleo de Estudos da Violência (NEV), na USP. ${ }^{2}$ Pensamos, também, em artigos escritos com a clara intenção de introduzir no debate a ação discricionária e violenta da polícia, sobretudo em seu contato com as camadas mais pobres da população (Paoli, 1982; Benevides, 1983).

Quando pesquisas mais sistemáticas sobre as polícias começam a configurar um campo específico e especializado, as análises passam a dar conta dos mecanismos internos e das lógicas de funcionamento das corporaçóes. São, de novo, os casos das pesquisas realizadas no âmbito do NEV; dos trabalhos de Roberto Kant de Lima, sobre os mecanismos de investigação da polícia civil do Rio de Janeiro (Kant de Lima et al., 1985); da seminal utilização da sociologia das organizaçôes por Antônio Paixão, para entender o modus operandi da Polícia Civil mineira (Paixão, 1982); e da singular imersão de Guaracy Mingardi para a compreensão dos mecanismos informais de operação dos policiais civis paulistas (Mingardi, 1999).

Talvez não seja mera coincidência que os primeiros trabalhos mais sistemáticos sobre corporações policiais tenham se voltado para as polícias civis. É possível que o caráter fortemente militarizado das polícias militares tenha produzido uma espécie de evitação inicial. Esta, contudo, foi contornada, e uma série de estudos etnográficos sobre formação (Poncioni, 1995; Caruso, 2004), sobre o ethos profissional (Muniz, 1999) ou sobre diferentes aspectos de seu desempenho (Rolim, 2012; Costa, 2004) se sucederam em um relativamente rápido processo de consolidação de um campo de estudos específico.

Em geral, as pesquisas referem-se a uma corporação específica em uma unidade da federação. Tratam-se, então, em sua maioria, de estudos mo- nográficos. As abordagens têm se diversificado, bem como os recursos metodológicos utilizados e as questôes priorizadas. A marca original do campo, porém, parece permanecer como traço comum compartilhado pela maioria dos trabalhos. Por um lado, a admissão das condiçōes ruins de funcionamento, bastante aquém do esperado seja do ponto de vista normativo, seja quanto aos resultados e desempenho alcançados. Por outro lado, o apego à tradição de funcionamento das corporações, o que se traduz nos péssimos padrões de interação com os segmentos populares da sociedade, padrôes esses marcados pelo uso abusivo da violência e da autoridade. Daí a incidência de análises com abertas pretensões reformadoras, o que faz com que interpretação e prescriçãoo estejam seguidamente uma ao lado da outra (Soares, 2000; Sapori, 2007). Em relação a esse último aspecto cabe destacar o relativo desinteresse nas discussōes sobre doutrina e mandato policiais. Relegadas à matéria mais afeita ao campo do direito, essas questóes apenas recentemente começam a despertar alguma atenção por parte dos pesquisadores do campo das ciências sociais, sobretudo em função dos debates sobre a desmilitarização das polícias militares e das vocações das polícias civis. ${ }^{3}$ Também aí as expectativas reformistas aparecem como a contraface do interesse propriamente analítico dos pesquisadores engajados no campo.

É difícil pensar como seria diferente. A última década do século passado e os anos posteriores testemunham a consolidação da segurança pública como um dos principais e recalcitrantes desafios à consolidação democrática no país, o que confirma o diagnóstico dos precursores do campo. No âmbito mais geral da segurança pública, elevada a tema central em políticas públicas, as polícias se consolidaram como um problema dos mais relevantes, desafiando analistas, formuladores e gestores.

O abuso da violência extralegal dirigido contra as classes populares, a corrupção amplamente difundida e quase institucionalizada e os baixos níveis de efetividade fazem com que as polícias gozem, ao longo dos anos, de baixíssimos índices de confiança. Essa tendência era apontada na década de 1990 em estudo, por exemplo, sobre São Paulo (Cardia, 1997); perpetua-se na primeira década do século XXI, em centros tão distantes geograficamente 
como o Rio de Janeiro (Sento-Sé, 2006) e Fortaleza (Barreira, 2004); confirma-se contemporaneamente como aponta recente resultado revelado pelo Índice de Confiança na Justiça Brasileira (ICJ) publicado pelo Fórum Brasileiro de Segurança Pública (2013). Para ficar apenas com os dados mais atuais, cumpre apontar que o ICJ Brasil, realizado pela Escola de Direito da Fundação Getúlio Vargas e apresentado no Anuário brasileiro de segurança pública, revela que $70 \%$ dos brasileiros declaram não confiar nas polícias. No que tange à confiança da população, as polícias só têm desempenho melhor do que os partidos políticos e o Congresso Nacional.

Embora sejam as classes populares as mais afetadas pela violência policial, em todas as pesquisas destacadas no parágrafo anterior (é difícil imaginar que haja algum trabalho que aponte diferenças significativas) a desconfiança, o medo e o ceticismo são os sentimentos que se alternam em rigorosamente todas as classes sociais, ainda que os trabalhos empíricos sobre relações entre polícia e sociedade se concentrem nos segmentos mais pobres da população. É nesse quadro geral que parte significativa dos estudos sobre polícia acaba revelando, explícita ou implicitamente, indisfarçáveis pretensões reformadoras. Daí, por outro lado, o espanto inicial da equipe de nossa pesquisa diante dos dados coletados. Daí, também, o interesse por eles despertado. Vejamos, então, por quê.

\section{Autoridade policial, riso e polidez}

A Operação Lei Seca é um programa de governo desenvolvido pela Secretaria de Governo do Estado do Rio de Janeiro (Segov). Seu desenho prevê a participação de diferentes instituições. As equipes são compostas por agentes da Polícia Militar, Detran e da própria Segov, tendo como órgãos auxiliares o Departamento de Transportes Rodoviários (Detro) e a Guarda Municipal, que participam apenas de ações específicas. Em seu formato original a operação era entendida como um recurso de conscientização sobre os riscos da associação entre álcool e direção de veículos automotivos. Posteriormente, adotou-se uma perspectiva mais repressiva e punitiva, lançando-se mão de abordagens mais próximas do trabalho policial propriamente dito. Atualmente, a constatação do uso de álcool por parte de um motorista flagrado na operação ou sua recusa em fazer o teste do bafômetro pode implicar desde a apreensão do veículo e suspensão da licença de direção até a autuação policial. ${ }^{4}$

Em trabalho anterior voltado para a análise da forma de exercício da autoridade pelos policiais integrantes da Operação Lei Seca, destacamos alguns traços centrais da concepção e da performance que apareciam recorrentemente nos relatos dos policiais. O primeiro traço é sua relação com a "ordem pública”: os policiais contam que a Operação Lei Seca não pode "perturbar" a ordem pública, e dão como exemplo decisōes de interromper uma operação para não causar engarrafamentos ou sua preocupação em não "estressar o cidadão", aceitando, dentro de alguns limites, eventuais "destemperos". Trata-se, assim, de uma concepção em que ao policiamento não cabe instaurar ou restaurar a ordem pública percebida aprioristicamente como dotada de um potencial para o caos, como é o caso de outras formas de intervenção policial; aqui, ao contrário, a "ordem pública” é, com o perdão da redundância, potencialmente "ordeira", não cabendo aos policiais perturbá-la. ${ }^{5}$

O traço fundamental da performance de autoridade policial na Lei Seca é a destituição de dois signos fundamentais da identidade policial, acionados comumente em diversas outras formas da atividade policial: o fuzil e a farda. Os policiais dessa operação não usam seu uniforme tradicional e portam somente um revólver em um coldre na perna, muitas vezes não percebido pelos cidadãos. Assim, uma dificuldade que relatam com frequência é de se fazer reconhecer/respeitar como policiais. Neste esforço, surge outro traço central dessa forma de exercício da autoridade policial: o recurso à polidez. Os policiais insistem muito na importância de serem "polidos", importância esta que aparece em seus depoimentos sob a forma (entre outras) do uso preferencial de verbos como "orientar", "instruir" ou mesmo "convidar" para relatar sua interação com os cidadãos, em vez de "ordenar" ou "obrigar", por exemplo.

Há ainda dois outros traços fundamentais de sua atuação: a demonstração do conhecimento da lei e a atuação emocionalmente imperturbável. 
Diante de eventuais contestações de sua autoridade, os policiais da Lei Seca dizem contorná-las recorrendo a uma demonstração tranquila e impessoal da rigorosa legalidade de seus procedimentos, explicados didaticamente a cidadãos que tentam se esquivar das implicações da abordagem. Há relatos ocasionais de interpelações ou atitudes desrespeitosas; indagados sobre suas reações emocionais diante disso, os policiais apresentam-se como "imperturbáveis", "profissionais", com uma "frieza" emocional entendida como não se deixar "atingir" pelo desrespeito no plano afetivo.

Nossa pesquisa incluiu ainda, além das entrevistas com policiais, o acompanhamento de algumas operações, quando presenciamos situações em que os policiais foram alvo de implicância e provocação jocosa por parte de cidadãos, sem que tenham reagido com qualquer forma de truculência. $\mathrm{O}$ inusitado dessa situação no Rio de Janeiro - cidadãos rindo de policiais sem suscitar neles qualquer reação agressiva - levou-nos a uma questão: que operação é essa em que a autoridade policial, destituída da farda e do fuzil, é exercida com polidez, frieza emocional e conhecimento da lei? Por que os cidadãos se sentem à vontade para provocar os policiais, rindo, implicando, eventualmente debochando?

A interpretação que propusemos então se baseou em uma combinação teórica que articulava teorias do riso com teses sobre a relação entre violência e polidez, sugerindo uma via para a compreensão do exercício da autoridade presente na Operação Lei Seca. Das teorias do riso (Bergson, s. d; Baudelaire, [1855] 1976; Bakhtin, 1993), retiramos a relação entre orgulho, vaidade e riso, propondo que "quem ri de quem" é uma forma de dizer "quem manda em quem"; das teorias da polidez, abstraímos o problema mais geral da relação entre polidez e violência, em que a primeira ora aparece como estratégia de contenção da violência (Elias, 1993), ora como meio para seu exercício, como que em sua forma extrema (Miho, 1993).

Recorrendo então às teses de Hannah Arendt sobre a demarcação da fronteira da autoridade por meio da exclusão da violência, bem como aos "diagnósticos" sobre a crise da autoridade no mundo moderno (Arendt, 2007; Sennett, 1982), propusemos uma interpretação dessa forma de concepção e per- formance da autoridade policial baseada na taxonomia dos atos de fala de Searle (1976). Nesta classificação, "convidar" e "ordenar" estão lado a lado na categoria dos verbos diretivos, ou seja, aqueles cuja ação no mundo é levar o outro a fazer algo; diferem, contudo, em sua "força ilocucionária", com o primeiro sendo brando e o segundo incisivo. E recuperamos aqui nossa conclusão daquele texto:

Ora, não estaria aqui uma chave explicativa para a centralidade da polidez como característica da autoridade policial, que substitui a "ordem" pelo "convite" ou pelo "conselho", em um movimento que simultaneamente instaura e oculta o exercício da autoridade? "Você me obrigou a fazer o teste. Não, eu convidei a fazer o teste. Ah, você me convidou, mas eu me senti obrigado": não seria este o sentido último da intuição fina de nosso entrevistado neste relato?

Não seriam, por fim, a polidez do policial e o riso do cidadão, duas estratégias possíveis diante da crise da autoridade, que dificulta ao mesmo tempo seu exercício e a submissão a ela (Coelho, Sento-Sé, Silva e Zilli, 2013, p. 919)?

\section{A sujeição à autoridade policial}

\section{O reconhecimento dos policiais}

$\mathrm{Na}$ Operação Lei Seca, os policiais encarregados de fazer a abordagem aos motoristas não utilizam o mug, fardamento tradicional da polícia militar do Rio de Janeiro. No lugar de seu uniforme característico na cor cinza, além de boots pretos e outras insígnias militares, eles utilizam o uniforme padrão da OLS, que também é trajado pelos demais agentes civis da Segov que participam da operação. Além disso, os policiais não fazem uso de nenhum tipo de armamento pesado, como o fuzil AR-15, que costuma ser portado em outros tipos de abordagens. $\mathrm{O}$ único elemento que os distingue visualmente, conforme já descrito, é uma pistola que trazem consigo num coldre amarrado à perna, o que nem sempre é percebido pelos cidadãos.

Desse modo, a imagem dos policiais em uma blitz da Lei Seca não condiz com a imagem que os cidadãos fluminenses estão acostumados em seu dia a dia. Isso dá margem a algumas confusōes e 
incertezas. Em nossa pesquisa, muitos entrevistados declararam que acreditavam não terem sido parados por policiais, ou que não sabiam ao certo a função ou a profissão da pessoa que os havia abordado, como mostram as seguintes passagens:

$\mathrm{Na}$ lei seca, eu já fiquei assim porque eu nunca tinha feito, tinha que saltar e tudo... do carro... Aí... não foi o policial, foi o... aquele... aqueles assistentes ali, que eu não sei o nome, né, da profissão ali deles, foram os assistentes que pediram... (entrevista 1).

É, na lei seca é... são os agentes né, da lei seca, não são... acho que não são policiais. Tem os policiais que ficam dando cobertura, e tal, mas é... são agentes, né... mas foi tranquilo, assim... eles são educados, né?” (entrevista 2).

$A$ abordagem não foi nem por um policial, foi pelo funcionário do Detran, e foi muito respeitoso. Não tenho quanto, nada quanto a reclamar por isso porque se tivesse eu faria junto ao funcionário, principalmente (entrevista 9).

Não... não me pareciam guardas. Não. Não, não pareciam, não, não eram. Não eram. Pessoas lá com aquele negócio lá, um colete lá que eles botam... não parece. Uniforme de policial não era (entrevista 5).

Por acreditar que não estava sendo abordada por um policial, essa última entrevistada diz ainda que se sentiu mais segura, ou melhor, mais "tranquila” durante a blitz da Lei Seca. Indagada se teria sentido medo em algum momento da abordagem, ela respondeu, comparando com um episódio a que assistira em uma blitz policial de outro tipo:

Não. Não, porque não era guarda, né? O que me marcou foi ver um guarda fazer aquilo, né? ${ }^{6}$ Quer dizer, o guarda que devia ser a pessoa que a gente deve recorrer quando precisa por uma questão de segurança, era exatamente a pessoa que tava fazendo a coisa errada, né. Aí... o vilão era ele, né... então... Lei Seca não é isso não.
Portanto, o fato de não utilizarem o uniforme tradicional faz com que os policiais não sejam reconhecidos pela população, ou melhor, que sejam confundidos com civis, contribuindo para gerar um maior sentimento de segurança ou tranquilidade durante a abordagem. No entanto, tais sentimentos não derivam unicamente desse fator, nem é esse o único elemento que faz com que a Operação Lei Seca seja diferente de outras formas de abordagem policial. Na blitz da Lei Seca, os cidadãos encontram ainda outro elemento que destoa fortemente da representação mais comum dos policiais feita pelos cidadãos fluminenses: a educação.

\section{A importância da "educação"}

Ao longo das entrevistas, os pesquisados destacaram a importância da "educação" dos policiais como uma das características mais marcantes da blitz da Lei Seca, em contraste com a truculência e os abusos que, em sua visão, marcam a ação dos policiais em outros tipos de operação. Como vimos, de acordo com o padrão diferenciado de abordagem proposto pela Operação Lei Seca, os policiais procuram colocar em prática um modelo de autoridade pautado pela polidez e pelo conhecimento das leis, o que parece ser reconhecido pelos cidadãos. De modo quase unânime, nossos entrevistados citaram e elogiaram o que consideram "maior preparo e educação" dos policiais responsáveis por conduzir sua abordagem quando foram parados. Isso pode ser observado nos seguintes depoimentos:

Então... me pararam, foram super educados, perguntaram se eu me incomo... pediram os documentos do carro, perguntaram se eu me incomodava de... de fazer o teste do bafômetro, e... saltei do carro... me mostraram lá o negócio esterilizado, tiraram do saco, não sei que lá, soprei... (entrevista 5).

Não, cara... eu, assim... até... sendo sincero, os policiais me pareceram bastante simpáticos... todos da Lei Seca, bem... certos, bem éticos... (entrevista 5).

É, todos eles são bem educados. Aborda a gente, pede para parar. É... Pede a habilitação, do- 
cumento do automóvel, e convida a fazer o teste do bafômetro. É... Não vejo assim nenhum tipo de agressão deles na própria fala, né? Pelo contrário, né? (entrevista 10).

Ela usou o bom senso, foi extremamente educada na abordagem e no final me deu um documento, um papel educativo. Então eu me senti muito bem, acho que não tem... acho, as pessoas, acho não, vejo que as pessoas que trabalham na lei seca são mais preparados, bem mais preparados, entendeu? E não usam da questão da lei para se sentir maior ou melhor do que as pessoas, do que as outras pessoas, entendeu? Eu vejo isso (entrevista 7).

Respeito, educação, gentileza e até mesmo simpatia são algumas das qualidades atribuídas pelos entrevistados aos policiais que participam da Operação Lei Seca. Os cidadãos destacam a educação presente no modo de falar dos policiais: eles cumprimentam, dizem "boa noite", solicitam sua colaboração, agradecem, despedem-se com saudações. Como destaca uma das entrevistadas, os policiais da Lei Seca não "mandam", eles "pedem", e essa parece ser uma diferença importante desse tipo de operação em comparação com outras formas de abordagem policial. Podemos dizer que o maior "preparo" e "polidez" dos policiais tem como efeito deixar os cidadãos mais "tranquilos". Isso está presente nos depoimentos de diversos entrevistados, mas pode ser visto com mais clareza nos seguintes trechos:

[...] aí eu tava supernervosa, ele "olha, não vai ser nada, tal, vamos ali dentro falar e tal... é só você se apresentar...", foi educado... aí me conduziu... aí falou assim "você quer fazer o bafômetro?". Falei "não, quero não...", aí ele "então você tem que arrumar alguém pra levar o carro” (Entrevista 3).

Eu achei que o pessoal da Lei Seca, pelo menos a pessoa que me abordou, me deixou totalmente tranquila... (Entrevista 3).

Mas foi muito tranquilo. Realmente... aquele ali realmente estava preparado. Porque num, hora nenhuma, quando... "Não, o senhor pensa bem, se o senhor não quiser assoprar o senhor não assopra, é um direito que o senhor tem. Isso não é obrigatório". Então ele foi bem tranquilo, bem tranquilozão. "Mas eu acho que não vai dar nada, não sei o quê, o senhor que sabe". Foi muito tranquilo, a abordagem foi... Pediu os documentos do carro, entendeu? Viu que o carro estava certinho, a minha carteira também de motorista. Foi tranquilo (entrevista 11).

Da varanda eu pude perceber que eles são extremamente educados com as pessoas, mesmo os que estão errados. Dizendo que "infelizmente", né, a pontuação foi acima do esperado, comunicavam as pessoas, deixavam as pessoas de repente ligar para alguém para vir buscar o carro ou para vir ajudar porque a pessoa estava nervosa e tudo. Eu achei super positivo, não vi em nenhum momento nenhuma ação, nenhuma condução da atividade de forma que fosse agredir a população. Isso eu vi de longe, não como participante. Então eu prefiro ser parado hoje pela Lei Seca do que por qualquer polícia hoje no dia a dia (entrevista 7).

A educação dos policiais, portanto, é um dos pontos mais destacados na visão dos cidadãos fluminenses sobre a blitz da Lei Seca. Esse é um dos principais diferenciais desse tipo de operação em relação às outras formas de abordagem policial, contribuindo para que ela seja aprovada e bem acolhida pela opinião pública. Ainda assim, ser parado pela polícia, seja numa blitz "normal" ou da Lei Seca, parece constituir sempre uma situação desconfortável para nossos entrevistados. Mais precisamente, eles parecem não se sentir à vontade ao serem considerados "suspeitos" pelos policiais. Veremos a seguir como eles lidam com isso.

\section{Eu, suspeito? Negociações performáticas}

Quando perguntados sobre os critérios adotados pelos policiais ao pararem os carros na blitz, nossos entrevistados afirmaram, em sua maioria, que acreditavam na aleatoriedade da ação. Ao mesmo tempo, muitos deles atribuíam a elementos como aparência, idade, companhias e estilo de carro uma explicação para terem sido retidos na Lei Seca, como pode ser observado nos trechos a seguir: 
É... tipo... meu carro chama um pouco de atenção, né... Meu carro, vermelho com aerofólio... então, parei em todas as Leis Secas [risos], todas, sem exceção (entrevista 2).

Então, eu vejo parando carro com mais de uma pessoa, né? Assim, casal, às vezes jovens, homens, rapazes dentro de carro e tal (entrevista 7).

Entrevistador - [...] E por que você acha que foi parada?

Entrevistada - Não sei, não tenho a menor ideia. Achei até engraçado né? Porque... sei lá... numa segunda-feira não é normal pra uma pessoa bêbada... vai sair, normalmente... como eu não bebo então eu acho que eu nunca poderia ser uma pessoa suspeita, porque... né? Mais vetha... né? Com uma jovem do lado... entendeu? Assim... pra mim era assim a pessoa menos suspeita pra alguém parar e pedir seria eu. Né? Cheio de jovem passando... enfim (entrevista 5).

Pode-se perceber como os entrevistados relacionam tais elementos a um perfil suspeito, neste caso, de estar dirigindo tendo ingerido álcool. Ter um carro esportivo e ser jovem seriam, portanto, exemplos de características que atribuiriam aos seus portadores uma condição suspeita. A fim de evitar ou suavizar tal condição, os entrevistados recorrem a um conjunto de práticas performáticas de visibilidade e identificação:

Entrevistadora - E essas outras blitz, assim, você faz algo, costuma fazer alguma coisa para não ser parado? De repente até no momento que você está já chegando e você vê que tem a blitz... Entrevistado - Se eu estiver no carro eu acendo a luz interna e abaixo o vidro. E de moto eu normalmente é... passo bem atento para eles, diminuo a velocidade, passo bem atento olhando para a cara, nos olhos de cada um, demonstrando que eu não tenho nada a temer (entrevista 9).

Quando eu cheguei e aí acendi a luz interna, eles perceberam que eu estava sozinho, estava de social, aí acho que descaracterizou a questão da possível motorista com bebida, né? (entrevista 7).
[...] eu tento... abrir o vidro... eu ligo... acendo a... é... a luz do carro... e pareço tranquilo, assim... Boto até... tem uns óculos no meu carro que eu boto direto. Aí eu boto os óculos... pra parecer que eu sou mais... intelectual, tá ligado? [risos] (entrevista 6).

A tentativa de se tornarem visíveis, mostrando que não têm "nada a temer" ou revelando características como estar "de social" ou ser "intelectual", demonstra um desejo de afastamento da condição e do perfil de suspeito. Esse desejo, motivado pelo desconforto que pode ser experimentado na retenção pela abordagem da Lei Seca, não parece surgir apenas nos casos em que o motorista é mesmo "culpado" e pode sofrer sanções legais. A própria inclusão na suspeita, confirmada ao serem parados pelos policiais e sujeitos à avaliação da conduta (neste caso, o teste do bafômetro) pode causar incômodo. Este será o tema da próxima seção.

Suspeito, eu? Dinâmicas emocionais das camadas médias cariocas

Embora a experiência da Lei Seca ocorra, na maioria das vezes, de forma cordial e sem maiores conflitos, alguns entrevistados relatam que se sentem envergonhados ou constrangidos ao serem parados e/ou terem que fazer o teste de embriaguez.

Não, assim... ah... é, na realidade a gente fica com vergonha de ter parado, assim, "porque que será que ele me parou?” Eu não sei porque que ele me parou (entrevista 1).

Entrevistadora - E constrangido você já falou que se sente um pouco, mas, só na situação da revista mesmo?

Entrevistado - Na revista e... e da exigência do exame.

Entrevistadora - Hum, da Lei Seca?

Entrevistado - Da Lei Seca (entrevista 9).

A menção a tais sentimentos, mesmo quando não tinham bebido e não se encontravam, portanto, passíveis de serem penalizados, revela um desconforto dos entrevistados com a suspeição momentanea- 
mente atribuída a eles, assim como com a necessidade de confirmá-la ou negá-la através da realização do exame. Como pode ser observado de maneira mais evidente nos depoimentos a seguir:

É, eu... eu acho que é um pouco afronta, assim... direito de ir e vir, acho que você... é... as blitz no Rio de Janeiro, todas são... é... não é legal. Acho que tem que fazer blitz com quem é suspeito, e não com... todas as pessoas aleatoriamente, pra pegar o... nivelar por baixo... "Ah, aquele cara deve tá bêbado, então, vamos pegar..." eu acho errado isso. Pra mim não... não é certo (entrevista 2).

É... Você, você tem que fazer prova a seu favor. Eu tenho que mostrar, está invadindo a minha privacidade, onde eu tenho que provar que eu não estou embriagado. Que eu não bebi, não é que eu não esteja embriagado, melhor dizendo, eu não bebi. Então eu acho que é... Não apoio essa forma de fazer. Você tem que sair do carro, você tem que ir lá soprar para fazer o negócio, para comprovar que você não, não atingiu aquela quantidade ali de álcool no sangue (entrevista 9).

No primeiro trecho, a negação da condição de suspeito faz o entrevistado rejeitar a própria realização da blitz com motoristas de forma geral, criticando a "aleatoriedade" da operação. No segundo, a insatisfação do entrevistado aparece em relação à necessidade de ter que "provar" sua inocência. Em ambos os casos, há dois traços importantes a destacar. O primeiro é o recurso a argumentos que acionam um discurso "jurídico", recorrendo a noções do universo legal, tais como "invasão de privacidade" ou "direito de ir e vir" para justificar seu desconforto com a condição de "suspeito", em uma espécie de "contraponto" ao uso do conhecimento legal como estratégia de construção de autoridade por parte dos policiais, conforme vimos anteriormente.

O incômodo com as práticas das blitze da Lei Seca parece estar ainda relacionado com uma crítica à generalização dos procedimentos, à submissão de todos os motoristas que por ela passarem e à possibilidade de serem considerados suspeitos e de terem suas condutas avaliadas de forma padrão. Tal crítica à desvalorização das peculiaridades individuais pode ser compreendida dentro dos processos de socialização e identificação predominantes nos indivíduos das camadas médias e altas urbanas, que tendem a rejeitar as normalizações generalistas e discricionárias em relação a si (DaMatta, 1979).

De qualquer forma, nossas entrevistas evidenciaram que a perspectiva de desconforto experimentada na Lei Seca é intensamente reduzida se comparada a outros momentos de interação com a polícia que nos foram relatados. A postura polida adotada pelos policiais, tanto na maneira como se portam como na forma como falam, parece contribuir muito para que o incômodo característico da posição "suspeita" seja diminuído.

\section{As representaçóes dos policiais}

As opiniōes positivas dos entrevistados sobre a Operação Lei Seca têm como contraponto fundamental suas representações sobre a atuação dos policiais no cotidiano, em outros tipos de blitz e de operação. Ainda que essa comparação nem sempre apareça de modo explícito, podemos dizer que ela se encontra sempre presente de modo subjacente nas declaraçóes dos entrevistados. Nesse sentido, só podemos compreender as imagens positivas na medida em que elas sejam colocadas em contraste com as imagens fortemente depreciativas construídas sobre a atuação da polícia em outras situações.

De acordo com os depoimentos, depreendemos que os cidadãos fluminenses nutrem sentimentos negativos em relação à polícia. Nas falas dos entrevistados, os policiais são representados como corruptos, violentos, truculentos e despreparados. Podemos identificar isso nas seguintes passagens:

Constrangido não, mas sempre passa alguma coisa... tipo, meu carro, com a documentação toda... toda legal, tudo direitinho, em dia, mas mesmo assim você tem uma... uma desconfiança que alguém vai... vai fazer alguma coisa contra você. Vai, tipo, vai achar alguma coisa no teu carro que tá irregular e você tem que parar 
e... tem que... sempre pensa isso, não tem jeito... é estranho, é uma sensação ruim, assim... não é bom (entrevista 2).

É... eu sempre... eu sempre... essa é minha postura sempre... eu evito... atrito, alguma coisa assim... porque... pelo histórico do Rio de Janeiro, eles... a gente... foi o que eu falei antes, a gente... eles... às vezes, eles podem querer conseguir.. arrumar alguma coisa contra você, assim... de alguma forma (entrevista 2 ).

Eu sempre penso assim, eu vejo uma blitz, meu pensamento é esse "pra que que eles tão precisando de dinheiro agora?!”. É... você pode ver, começa a chegar uma fe-, uma data importante, natal, dia dos pais, dia das mães, seja lá o que for, e eles arrumam um jeito de ter blitz aqui, blitz ali, pra poder arrecadar dinheiro. Eu acredito que sim, nunca fui abordada, não, mas eu acredito que é um meio de ganhar dinheiro, sim (entrevista 3).

Ah, a gente sempre fica, né? Acho que hoje em dia tá muito... tudo muito violento. E muitos policiais também não estão preparados, né? Tendo a ver do próprio salário dos caras, né? Então, eles têm uma preparação muito baixa e qualquer coisinha eles estão nervosos, esse negócio todo. Entendeu? Então eu creio que é mais culpa mesmo... precisando uma preparação melhor para eles (entrevista 11).

Em vez de serem vistos como responsáveis pela garantia de proteção, tranquilidade e segurança, os policiais são representados, muitas vezes, como uma ameaça à população. Ao contrário dos agentes da Lei Seca, eles não teriam tato para lidar com os cidadãos, seriam ríspidos, tratariam a todos previamente como bandidos, forjariam provas contra pessoas inocentes. Nesse sentido, suscitam sentimentos como medo e desconfiança:

Eu fiquei um pouco com medo, só... na hora... porque, pô, o cara... vai que o cara... é... arma alguma coisa, e fala que achou maconha no meu carro é... ou fica, sei lá... cismado com o meu protetor solar, alguma coisa do tipo, sabe? Não sei... na hora eu fiquei um pouco com medo (entrevista 6).

Assim... tem algumas coisas que eu acho que eles são... que eu acho desnecessário, por exemplo... eles... a gente vê na rua, a gente anda na rua os policiais de fuzil direto, assim... acho desnecessário ter um fuzil, é... transmite, na minha opinião, pra população, um pouco de... a gente tá em guerra sempre, é... tipo, assim... que o policial pode... sem querer, matar alguém... não sei... eu acho que transmite isso um pouco pra população, um pouco... dá um pouco de medo na população... eu não sei se essa é a ideia de ter os policiais andarem de fuzil ou não... porque não precisa andar de fuzil, pode andar com uma pistola... não sei... (entrevista 6).

Mas a relação dela com a sociedade e com as pessoas é muito ruim, é muito ruim. $\mathrm{E}$ as pessoas que eu conheço têm certo receio da Polícia Militar. Eu sei que é um absurdo, mas dizer que tem mais medo da Polícia Militar do que de bandido, de ser abordado pela Polícia Militar do que por bandido... (entrevista 7).

Sinceramente, essa polícia não serve para a sociedade. Ela está ali fazendo um bem, porque ela garante uma ordem porque... Sei lá a desordem está maior do que... Mas por outro lado a população se sente mal. Eu não vejo ninguém se referindo a um policial militar de forma amigável, não vejo. Eu pelo menos não conheço ninguém. As pessoas precisam deles, nós precisamos deles e recorremos ao policial militar e até civil também, eu estou falando Polícia Militar, mas a Polícia Civil também (entrevista 7).

A atuação da polícia em condições "normais" é marcada, pois, pela truculência e pelo desrespeito com os cidadãos. As representações negativas sobre a polícia nos permitem compreender a valorização da educação e do "preparo" pouco habitual demonstrado pelos agentes da Lei Seca. Trata-se de modelos opostos de construção da autoridade policial: a primeira, imposta de modo 
truculento; a segunda, pautada na polidez e no conhecimento das leis. Como os cidadãos reagem a isso? Veremos a seguir.

\section{A relação com a autoridade}

Embora a autoridade policial esteja fundada na lei, sendo algo juridicamente instituído, seu significado parece estar sujeito a negociaçôes nas cenas de interação entre policiais e cidadãos. Ou seja, se os policiais impóem sua autoridade de modo truculento nas abordagens "normais", ou a conquistam de modo "educado" nas operações da Lei Seca, isso sugere que o significado dessa autoridade não é unívoco, isto é, seus limites são fluidos. Diante da recorrência de abusos que marcam a atuação da polícia e, por conseguinte, as imagens que os cidadãos constroem sobre ela, nossos entrevistados tiveram dificuldades para identificar a ocorrência de casos de "abuso de autoridade" nas experiências vivenciadas por eles:

... foi... foi o que eu entendi, que... assim... abuso de autoridade... de um modo geral... constituição... acho que o cara apontar uma arma pra você.... já é abuso de autoridade, mas... eu acredito que aquilo ali não seja visto como abuso de autoridade nos padróes que é no Rio de Janeiro (entrevista 2).

Tipo, aquilo ali é normal... então, abuso de autoridade seria se ele te desse uma coronhada com a arma, ou alguma coisa assim... mas... mais do que aquilo ali que ele já tá fazendo... pra mim... é... o entender deles, da polícia, de abuso de autoridade, é outro, do que a gente pode entender, talvez, como.... população geral, assim... a gente... qualquer coisa, abordagem a mais pra... pra gente já é abuso de autoridade, né... (entrevista 2 ).

É... na minha opinião, eu acho que é um pouco de abuso de autoridade, porque... assim... o procedimento certo a ser feito, na minha opinião, é perguntar se podia ser... se ele podia revistar o carro. Se eu falasse que não, aí a gente estaria num impasse, eu não sei te dizer exatamente... o que aconteceria... mas o procedimento cer- to, ele perguntaria “posso revistar o carro?”. Eu falaria sim, provavelmente, né... (entrevista 6).

Então é a abordagem. Meio abusado, é..."Saia do carro!" Não é? "Seus documentos! Tira de dentro da... Tira da...” Às vezes está no, tipo uma carteirinha de plástico. “Tira daí!" Como se eu fosse um, né? Estivesse devendo alguma coisa a ele, né? Então tudo isso estressando o cidadão que pode no momento, ser realmente... tomar uma atitude errada e aí ele pode enquadrar como desacato à autoridade. Então você fica entre ser humilhado ou ser enquadrado como desacato à autoridade. Então, não tem opção, entendeu? Esse é o abuso da Polícia Militar (entrevista 7).

Os entrevistados hesitam em assumir uma postura mais assertiva, mesmo quando classificam como exemplos de "abusos" algumas situações pelas quais passaram. Em sua perspectiva, haveria uma discrepância entre aquilo que eles definem como "abuso" e a definição mantida pelos policiais; ao mesmo tempo, a atuação da polícia teria um caráter habitualmente "abusivo", ou seja, como o abuso faria parte do procedimento "normal" dos policiais, ele só é identificado quando ocorre algum tipo de "excesso". Temos, então, definições de "abuso" que podem passar por uma "quantificação" ("um pouco de abuso de autoridade"), por seu efeito sobre o cidadão ("estressando o cidadão") ou mesmo pelo recurso à violência física ("uma coronhada com a arma"), escapando aos limites legalmente prescritos para a atuação policial.

Em trabalho dedicado ao mapeamento das relações entre poder e status, por um lado, e a emergência de sentimentos tais como humilhação, orgulho, vergonha etc., por outro, Kemper define a autoridade como uma forma institucionalizada de poder. A autoridade seria "marcada pela legitimidade, o que significa que aqueles que se encontram dentro do escopo da autoridade concordam em acatar reivindicações ou ordens consideradas dentro do raio de alcance do poder delimitado" (Kemper, 2001, p. 61). Na sequência de seu argumento, o autor faz uma observação que nos conduz diretamente ao âmago das tensões geradas nas interações entre policiais e cidadãos: "em relação às emoções geradas pelo poder, a autoridade é uma zona cin- 
zenta, já que aqueles que a detêm e aqueles que a ela estão submetidos muitas vezes discordam quanto à fronteira entre ordens legítimas e ilegítimas, e quanto ao que constitui coerção" (Idem, ibidem).

\section{À guisa de conclusão: as ciências sociais e o amor pelo conflito}

$\mathrm{Na}$ conclusão de seu estudo sobre a comunidade de Winston Parva, Norbert Elias defende a visão de que a definição dos temas "nobres" da sociologia seria perpassada por juízos de valor. Elias desenvolve esse ponto analisando a presença de posturas valorativas no estudo da anomia na obra de Durkheim (1982) sobre o suicídio. $\mathrm{O}$ estudo do suicídio teria servido como caminho para a constatação de um aumento da "anomia", conduzindo a um pessimismo diante do futuro da humanidade diante dos processos de industrialização e modernização:

Comparadas com o passado, as condições pareciam haver-se deteriorado, apesar - ou talvez por causa - dos avanços da indústria. Assim, desde o começo, a "anomia" teve implicaçōes valorativas específicas. Tinha toques de desilusão com a sociedade industrial urbana em que estávamos vivendo. Continha uma sugestão de que as condições haviam se deteriorado, um vago sentimento de que estavam ficando piores do que tinham sido, e de que o passado devia ter sido melhor do que o presente. Desde então, ligou-se a esse conceito um sopro de saudade de um passado mais risonho e agora perdido, no qual não havia "anomia" - um passado que nunca existiu (Elias, 2000, p. 178).

O conceito de "anomia" tem como seu avesso a ideia de "coesão". Ressurge aqui, segundo Elias, a valoração moral na própria eleição dos objetos dignos da atenção sociológica, ou seja, aqueles comprometidos com a compreensão e eventual intervenção em tudo o que é entendido como "problema":

Com a habitual concentração dos interesses da pesquisa nas dificuldades pelas quais o indivíduo é assaltado e com sua relativa indiferença pelos fenômenos sociais que não parecem apresentar dificuldades, poucos estudos, se é que algum, dedicaram-se especificamente a grupos não anômicos, pelo fato de eles serem não anômicos. Com frequência, a "nomia" e a coesão social foram implicitamente concebidas apenas como fatores morais, como algo positivo e bom, a ser contrastado com a "anomia" e a "falta de coesão", que eram - e provavelmente continuam a ser - concebidas por muitos não como uma configuração social específica, acima de tudo, mas como uma censura moral (Idem, pp. 178-179).

Haveria, assim, no entender de Elias, um desinteresse sociológico por tudo aquilo que "funciona bem":

Desde o começo, a escolha dos temas de pesquisa é influenciada por juízos de valor externos e, como se pode constatar, o que é tido como "ruim" tende a ser preferido como tema de pesquisa ao que é visto como "bom". Há uma preocupação com tudo o que cria dificuldades, não se dando tanta importância ao que parece estar correndo bem. Levantam-se perguntas sobre o primeiro caso: as coisas "ruins" pedem explicações, mas as "boas", aparentemente não (Idem, p. 180)

Entretanto, fenômenos "nômicos" e "anômicos" guardam uma relação lógica de interdependência, não podendo, portanto, ser plenamente compreendidos um sem referência ao outro. Novamente em suas palavras:

Em termos do que se observa na prática, a divisão dos temas de pesquisa conforme eles se refiram a "disfunções" ou a "funções" é inteiramente artificial. Equivale a separar problemas de pesquisa que, na verdade, são estreitamente ligados e amiúde inseparáveis, em consequência dos diferentes valores que lhes são atribuídos. Não se pode esperar encontrar explicações para o que se julga "ruim", para um "mau funcionamento" da sociedade, quando não se é capaz de explicar, ao mesmo tempo, aquilo que se avalia como "bom", "normal" ou "funcionando bem”, e vice-versa (Idem, pp. 180-181). 
É tempo, então, de nos perguntarmos: o que Winston Parva tem a ver com a Operação Lei Seca? $\mathrm{Ou}$, colocando de forma mais pertinente, qual a relação entre essas consideraçōes teóricas abstraídas por Elias a partir de Winston Parva e nossa descrição da relação dos cidadãos com a abordagem policial na Operação Lei Seca?

$\mathrm{Na}$ introdução deste texto, comentamos brevemente sobre a impressão de ausência de divergências nos relatos de cidadãos e policiais sobre a Operação Lei Seca. Ora, opinião pública, mídia, especialistas, gestores, policiais, os depoimentos de todos esses atores do campo da segurança pública costumam ser perpassados por um tom de denúncias e acusaçôes, em um tipo de relato que apresenta a interação polícia-cidadãos como inextricavelmente definida como conflito. Aquela impressão geral de "harmonia", recorrente na leitura de todos os membros da equipe, produziu de saída um desconforto intelectual: o que fazer com esse material? Como tratar sociologicamente essa impressão de "desinteresse" que a primeira leitura suscitou?

O esforço que fizemos, na melhor tradição antropológica, foi de natureza autorreflexiva: se o "objeto" não nos motiva intelectualmente, busquemos então outra inspiração intelectual. De onde ela vem? Da harmonia, da falta de conflitos dramáticos, da aparente concordância em traços gerais entre policiais e cidadãos, esses personagens que estamos, ao menos no Rio de Janeiro, tão acostumados a ver escalados como antagonistas em tramas já velhas conhecidas?

Não havia relatos de conflitos caudalosos, prisōes espetaculares, graves violaçóes de direitos ou acusaçōes de desacato à autoridade; no máximo, alguns incômodos quanto a se ver na condição de "suspeito", algumas queixas débeis quanto aos "excessos" da Lei Seca e muitos, muitos elogios à "educação" dos policiais no trato com os cidadãos. Em linhas gerais, a impressão era de que os relatos de policiais e cidadãos pareciam "concordar" na forma como descreviam/vivenciavam a Operação Lei Seca: os policiais nem sempre são reconhecidos como tais, devido à ausência da farda, são educados e respeitam o cidadão. É como se a ausência de conflitos graves no plano da interação - abundantes relatos de abuso e/ou de desacato à autoridade - se reproduzisse no plano discursivo, com este "espelhamento" entre as duas formas de narrar.
Mas talvez justamente por isso os dados tenham nos instigado. Cidadãos que aprovam a atitude de policiais? Cidadãos que os elogiam? Cidadãos que acatam suas ordens sem maiores reaçôes ou reclamaçōes? E tudo isso na cidade do Rio de Janeiro? Ora, o inusitado desse cenário, se comparado à proliferação de relatos e denúncias que povoam a mídia e o imaginário popular contra os mais variados tipos de violência policial, poderia ter nos entusiasmado pela descoberta de um "objeto sem precedentes na literatura especializada": uma operação policial elogiada e acatada por seu público-alvo.

A razão de nosso "desânimo" inicial é bastante óbvia: o compromisso sociológico com a investigação, a denúncia e a intervenção naquilo que funciona "mal", ou, colocando de outra maneira, a atração dos cientistas sociais pelo conflito. A Operação Lei Seca parece ser um caso raro em que uma iniciativa de policiamento no Rio de Janeiro funciona "bem" - opinião pública favorável, indicadores promissores de redução de acidentes de trânsito associados ao consumo de álcool, publicados na mídia etc. É isto que, paradoxalmente, torna a Operação Lei Seca invisivel como objeto de reflexão sociológica, em um extraordinário contraste com o interesse despertado na comunidade científica por um "projeto rival" (em termos de visibilidade midiática): as unidades de Polícia Pacificadora.

Mas por que isto acontece? A resposta, parece-nos, reside naquela diretriz-mor da agenda de pesquisa sobre violência urbana, policiamento e segurança pública nas ciências sociais brasileiras discutida na primeira seção deste artigo: o ideário dos direitos humanos. A agenda parece estar impregnada pela defesa dos direitos humanos, o que faria, então, com que somente episódios de violação fossem dignos de interesse. Uma polícia que se apresenta e é considerada incorruptível, não truculenta, polida, afeita ao cumprimento estrito da lei ficaria, justamente por realizar o ideal propalado em tantas instâncias discursivas sobre policiamento, ofuscada em seu potencial de esclarecimento sociológico. $\mathrm{Ou}$ será que o compromisso com a crítica e a denúncia é tão acirrado na agenda de pesquisa que impede o estudo daquilo que, ao que tudo indica e ao menos até o momento (e essas ressalvas cuidadosas são o tributo que pagamos a essa tendência das ciências sociais), vem dando certo? 


\section{Notas}

1 Dos doze entrevistados, oito eram homens e quatro, mulheres, com idades que variavam entre 23 e 58 anos. Todos residiam na região metropolitana do estado do Rio de Janeiro, predominantemente em bairros de classe média, como Copacabana, Barra da Tijuca, Recreio dos Bandeirantes, Itaipu etc. Em termos socioeconômicos, os entrevistados podem ser localizados nas classes A e B, com rendas familiares girando em torno de oito a trinta salários mínimos. Em sua maioria, possuíam o ensino superior completo, atuando nas seguintes profissōes: advogado (1), analista administrativo (1), analista de engenharia (1), assistente financeiro (1), dentista (1), músico (2), pastor evangélico (1), professora (1), representante comercial (2), técnica de enfermagem (1).

2 Para um quadro geral do NEV, ver Mesquita Neto (1997).

3 A propósito desses temas, vale a consulta à revista e outras publicações do Fórum Brasileiro de Segurança Pública.

4 Para uma descrição mais detalhada sobre a Operação Lei Seca no Rio de Janeiro e em âmbito nacional, ver Coelho, Sento-Sé, Silva e Zilli (2013)

5 Cabe destacar que a análise da questão da autoridade no contexto da Operação Lei Seca introduz um elemento diferenciado na área de estudos sobre polícia. Como já foi apontado, esse campo de estudos surge sob a égide do processo da redemocratização e da denúncia do caráter despótico e brutal do tratamento concedido às classes pobres pelas forças policiais. No contexto da Operação Lei Seca, o contato se dá preferencialmente com setores de classe média, o que explica, ainda que apenas parcialmente, os procedimentos mais alinhados às normas legais e o recurso à polidez como instrumento de autoridade, em lugar da intimidação e do uso desproporcional da força, tradicionalmente acionados sobre as camadas populares.

6 Refere-se a uma ocasião na qual teria presenciado um policial forjando provas contra dois jovens inocentes: durante uma revista de automóvel, ela teria visto o guarda deixar cair um saco branco do bolso de seu casaco, exibindo-o depois como evidência para puni-los - ou extorqui-los - por porte de drogas.

\section{BIBLIOGRAFIA}

ARENDT, Hannah. (2007), Entre o passado e o futuro. São Paulo, Perspectiva.
BAKHTIN, Mikhail. (1993), A cultura popular na Idade Média e no Renascimento: o contexto de François Rabelais. São Paulo/Brasília, Hucitec/ Editora da Universidade de Brasília.

BARREIRA, Cesar. (2004), "Em nome da lei e da ordem: a propósito da política de segurança pública”. São Paulo em Perspectiva, 18 (1): 77-88.

BENEVIDES, Maria Victoria. (1983), Violência, povo e polícia: violência urbana no noticiário da imprensa. São Paulo, Brasiliense.

BERGSON, Henri. (s. d.), O riso. Lisboa, Guimarães.

BAUDELAIRE, Charles. ([1855] 1976), "De l'essence du rire", in tes, Paris, Gallimard, vol. 2.

CARDIA, Nancy. (1997), "O medo da polícia e as graves violações dos direitos humanos". Tempo Social, 9 (1): 249-265.

CARUSO, Haydée Glória Cruz. (2004), Das práticas e dos seus saberes: a construção do "fazer policial" entre as praças da PMERJ. Dissertação de mestrado, Programa de Pós-graduação em antropologia e ciência política da Universidade Federal Fluminense, datilo.

COELHO, Maria Claudia; SENTO-SÉ, João Trajano; SILVA, Anderson Castro \& ZILLI, Bruno. (2013), "Autoridade policial, riso e polidez: notas sobre interações entre polícias e cidadãos na Operação Lei Seca no Rio de Janeiro". Análise Social, 209 (XLVIII): 900-920.

COSTA, Arthur Trindade Maranhão. (2004), Entre a lei e a ordem. Rio de Janeiro, 2004.

DAMATTA, Roberto. (1979), Carnavais, malandros e heróis. Rio de Janeiro, Zahar.

DURKHEIM, Émile. (1982), O suicídio. Rio de Janeiro, Zahar.

ELIAS, Norbert. (1993), O processo civilizador. Rio de Janeiro, Zahar.

(1995), Mozart: sociologia de um gênio. Rio de Janeiro, Zahar. (2000), Os estabelecidos e os outsiders. Rio de Janeiro, Zahar. . (2001), A solidão dos moribundos. Rio de Janeiro, Zahar.

FÓRUM BRASILEIRO DE SEGURANÇA PÚBLICA. (2013), Anuário Brasileiro de Segurança Pública, 7. 
KANT DE LIMA, Roberto; VARELLA, Alex; LESSA, R. \& CUNHA, R. M. C. (1985), "Polícia e democracia: controle social e administração da justiça”. Revista $O A B, 22:$ 279-286.

KEMPER, Theodore. (2001), "A structural approach to social movement emotions", in J. Goodwin, J. Jasper e F. Polletta (orgs.), Passionate politics: emotions and social movements, Chicago/Londres, University of Chicago Press.

MESQUITA NETO, P. (1997), "A experiência do núcleo de estudos da violência da USP". Comunicação \& Educação, 9: 107-111.

MIHO, Moto. (1993), "Barragem contra a violência", in R. Dhoquois (org.), A polidez, Porto Alegre, L\&PM.

MINGARDI, Guaracy. (1999), Tiras, gansos e trutas. cotidiano e reforma na Polícia Civil. São Paulo, Scritta.

MUNIZ, Jacqueline. (1999), Ser policial é sobretudo uma razão de ser. Tese de doutoramento, Rio de Janeiro, Iuperj, datilo.

PAIXÃO, Luiz Antonio. (1982), "A organização policial numa área metropolitana”. Dados: Revista Brasileira de Ciências Sociais, 25 (1): 63-85.

PAOLI, Maria Célia (org.), A violência brasileira, São Paulo, Brasiliense.

PINHEIRO, Paulo Sérgio. (1982), "Polícia e crise política”, in Maria Célia Paoli (org.), A violência brasileira, São Paulo, Brasiliense.

PONCIONI, Paula. (1995), A polícia e os pobres: representaçôes sociais e práticas em delegacias de polícia do Rio de Janeiro. Dissertação de mestrado, Universidade Federal do Rio de Janeiro, datilo. . (2003), Tornar-se policial: a construção da identidade profissional do policial no estado do Rio de Janeiro. Tese de doutorado, Universidade de São Paulo, datilo.

RAMOS, Silvia. (2005), Elemento suspeito: abordagem policial e discriminação na cidade do Rio de Janeiro. Rio de Janeiro, Civilização Brasileira.

RATTON, José Luiz \& BARROS, Marcelo. (2007), Policia, democracia e sociedade. Rio de Janeiro, Lumen Juris.

ROLIM, Marcos. (2012), A sindrome da rainha Vermelha. Rio de Janeiro, Zahar.

SAPORI, Luís Flávio. (2007), Segurança pública no Brasil. Rio de Janeiro, Editora da FGV.
SEARLE, J. (1976), "A classification of illocutionary acts". Language and Society, 5 (1): 1-23.

SENNETT, Richard. (1982), La autoridad. Madri, Alianza.

SENTO-SÉ, João Trajano. (2006), "Práticas e questōes em cidadania no Rio de Janeiro: uma questão em aberto". Cadernos de Cidadania, 2: 49-52.

SOARES, Luiz Eduardo. (2000). Meu casaco de general: 500 dias no front da segurança pública do Rio de Janeiro. São Paulo, Companhia das Letras. 


\section{A EXPERIÊNCIA DA SUJEIÇÃO À AUTORIDADE POLICIAL: NOTAS SOBRE A ARTICULAÇÃO ENTRE COGNIÇÃO E EMOÇÃ̃ NA VIDA PÚBLICA}

\author{
Maria Claudia Coelho, João Trajano \\ Sento-Sé, Raquel Brum e Fábio Rios \\ Palavras-chave: Autoridade policial; Emo- \\ ções; Operação Lei Seca; Policiamento.
}

Este trabalho aborda a experiência da autoridade policial do ponto de vista da sujeição, com base em relatos de cidadãos de camadas médias e altas, moradores do estado do Rio de Janeiro. Foram realizadas entrevistas em profundidade com pessoas que passaram por abordagens policiais em blitze da Lei Seca. O objetivo é investigar a articulação nessas experiências entre os planos cognitivo (concepçōes de autoridade, legalidade, poder, violência etc.) e emotivo. A análise busca contribuir com o campo de estudo das emoçóes na vida pública e com o campo de estudos sobre policiamento. $\mathrm{O}$ artigo discute ainda, à luz das observações de Norbert Elias, o impacto da centralidade do conflito sobre o estudo do policiamento nas escolhas de objeto nas ciências sociais.

\section{THE EXPERIENCE OF SUBMISSION TO POLICE AUTHORITY: NOTES ON THE ARTICULATION BETWEEN COGNITION AND EMOTION IN PUBLIC LIFE}

Maria Claudia Coelho, João Trajano
Santo-Sé, Raquel Brum, and Fábio Rios

Keywords: Police authority; Emotions; Dry law operation; Policing

The article analyzes the experience of submission to police authority through in-depth interviews with citizens of middle and high strata of Rio de Janeiro who have been subjected to police stops in blitzes related to the Lei Seca. Its purpose is to investigate in those experiences the articulation between cognitive and emotional aspects, that is, how cognitive aspects (concepts of authority, legality, power, violence, etc.) are intertwined with emotional dimensions. In so doing, the article seeks to contribute to the study of emotions in public life as well as to the field of studies on policing. Finally, based on Norbert Elias observations, the article discusses the impact on policing studies of the central role occupied by conflict in the choice/construction of research objects in the social sciences.

\section{L'EXPÉRIENCE \\ D'ASSUJETTISSEMENT À \\ L'AUTORITÉ POLICIÊRE: NOTES À PROPOS DE L'ARTICULATION ENTRE LA COGNITION ET L'ÉMOTION DANS LA VIE PUBLIQUE}

Maria Claudia Coelho, João Trajano
Sento-Sé, Raquel Brum et Fábio Rios

Mots-clés: Autorité policière; Émotions, Opération Loi Sèche; Surveillance policière.

Ce travail aborde l'expérience de l'autorité policière du point de vue de l'assujettissement et sur la base des récits des citoyens des couches moyennes et hautes, habitants de l'état de Rio de Janeiro. Nous avons utilisé des entretiens avec des personnes qui ont subi des abordages policiers au cours de contrôles de la Loi Sèche. L'objectif est de rechercher l'articulation dans ces expériences entre les plans cognitif (conceptions d'autorité, légalité, pouvoir, violence, etc.) et émotif. Lanalyse tente de contribuer avec le domaine d'études des émotions dans la vie publique et avec le domaine des études à propos de la surveillance policière. L'article aborde également, à la lumière des observations de Norbert Elias, l'impact sur l'étude de la surveillance policière de la centralité du conflit dans les choix objets des sciences sociales. 